\title{
A Contribuição de Uma Disciplina Acadêmica no Processo de Autonomização de Professores de Inglês em Formação
}

\section{The Contribution of an Academic Subject in the Autonomization Process of English Teachers in Training}

DOI: $10.46814 / \operatorname{lajdv} 3 n 4-054$

Recebimento dos originais: 01/05/2021

Aceitação para publicação: 31/06/2021

\section{Isabelly Raiane Silva dos Santos}

Mestranda em Letras pelo Programa de Pós-graduação em Letras (PPGL) da Universidade Federal do Pará (UFPA)

Docente no Instituto Federal de Educação, Ciência e Tecnologia do Pará (IFPA)

Endereço institucional: Rodovia Ernesto Acyoli, S/N, Km 3 - Nova Colina, Altamira-PA, Brasil

E-mail: isabelly.santos@ifpa.edu.br

\section{RESUMO}

No contexto da globalização, a língua inglesa vem ganhando gradativamente mais notoriedade no cenário mundial, fato que a leva a ser alvo de questionamentos que servem de base para o início de uma pesquisa. Desse modo, este estudo busca demonstrar a importância e os benefícios da aprendizagem autônoma desta língua estrangeira com base em definições e conceitos relacionados à autonomia e à motivação propostos por autores como Dickinson (1994), Ushioda (1996) e Benson (2001). Partindo desses referenciais teóricos, uma turma de calouros foi analisada durante o período no qual a disciplina Aprender a Aprender Língua Estrangeira foi ministrada como componente curricular obrigatório do curso de graduação em Licenciatura em Letras com habilitação em Inglês ofertado pela Faculdade de Letras Estrangeiras Modernas (FALEM), na Universidade Federal do Pará (UFPA), durante o segundo semestre de 2014. Tendo a docente como um dos principais agentes motivadores, ao final da disciplina, foram observados altos níveis de motivação em grande parte dos alunos. Ao final da investigação, tornou-se evidente que a aprendizagem pode ser mais efetiva quando o aprendente passa a compreender o funcionamento do processo cognitivo e a conhecer seu próprio estilo de aprendizagem.

Palavras-chave: Aprendizagem de inglês. Autonomia. Motivação.

\begin{abstract}
In the context of globalization, the English language has been gradually gaining more notoriety on the world stage, a fact that makes it the target of questions that serve as a basis for the beginning of a research. Thus, this study aims to demonstrate the importance and the benefits of an autonomous learning of this foreign language based on definitions and concepts related to autonomy and motivation proposed by authors such as Dickinson (1994), Ushioda (1996) e Benson (2001). Based on these theoretical references, a class of freshmen was analyzed during the period in which the subject Learn to Learn a Foreign Language was taught as a mandatory curriculum component of the undergraduate course in Majoring in English Language offered by the Faculty of Modern Foreign Languages (FALEM), at the Federal University of Pará (UFPA), during the second semester of 2014. With the teacher as one of the main motivating agents, at the end of the course, high levels of motivation were observed in most students. At the end of the investigation, it became evident that learning can be more effective when the learner starts to understand the functioning of the cognitive process and to know his/her own learning style.
\end{abstract}


Keywords: Autonomy. English Learning. Motivation.

\section{INTRODUÇÃO}

De acordo com o projeto pedagógico aprovado pela Resolução $n^{\circ}$. 3.931, de 22 de janeiro de 2010, no curso de graduação em Licenciatura em Letras com habilitação em Inglês ofertado pela Universidade Federal do Pará (UFPA), a disciplina obrigatória Aprender a Aprender Língua Estrangeira, comumente oferecida aos discentes no primeiro semestre do percurso acadêmico, tem como objetivos principais: analisar a aprendizagem, estimular o interesse do aluno pela língua estrangeira, distinguir estilos e estratégias de aprendizagem e conhecer os diversos fatores que influenciam na aprendizagem de línguas.

Desse modo, torna-se relevante a análise e a compreensão dessa disciplina sob o ponto de vista dos próprios alunos que a cursaram, uma vez que ela é posta como uma das bases necessárias para que o curso de graduação transcorra de forma completa, objetivando a capacitação do professor de língua estrangeira para uma futura atuação bem-sucedida dentro de sala de aula.

Assim, a pesquisa relatada neste artigo visa demonstrar a importância da interação entre a parte teórica e a parte prática da disciplina em questão, bem como elencar as melhores práticas para a formação do estudante crítico e capaz de guiar sua própria aprendizagem em um ambiente instável e não linear: o meio acadêmico.

Ao final, são demonstrados os resultados obtidos a partir da investigação acerca da adoção de técnicas e recursos os quais almejavam instigar, auxiliar e facilitar as etapas do processo de aprendizagem, provando que o adquirir de uma língua estrangeira pode ser realizado de maneira simples, cativante e motivadora, e compreendendo a importância e o papel da autonomia neste processo, visto que ela se caracteriza como uma "atitude com relação à aprendizagem" (DICKINSON, 1994, p. 2).

Esta pesquisa possui como objetivo geral demonstrar a importância e os benefícios da aprendizagem autônoma da língua inglesa com base em definições e conceitos relacionados à autonomia e à motivação. Dentre os objetivos específicos, é possível mencionar: 1) Identificar as técnicas utilizadas dentro de uma sala de aula tendo como objetivo o processo de autonomização discente. 2) Descrever o papel desempenhado pela motivação no contexto da aprendizagem de línguas. 3) Relatar os fatores que podem influenciar o estabelecimento e a continuidade da aquisição de uma língua estrangeira.

A partir das reflexões teóricas, foram gerados questionamentos que guiaram e firmaram-se como alvo da pesquisa, dentre eles: 1) Quais são as técnicas utilizadas dentro de uma sala de aula tendo 
como objetivo o processo de autonomização discente? 2) Qual é o papel desempenhado pela motivação no contexto da aprendizagem de línguas? 3) Quais fatores podem influenciar o estabelecimento e a continuidade da aquisição de uma língua estrangeira?

Além desta introdução, este artigo científico está organizado da seguinte maneira: na próxima seção, são abordados conceitos relevantes para a construção da base teórica da pesquisa, que foi proposta a partir do estudo de textos elaborados tanto por autores brasileiros quanto estrangeiros. Em seguida, a metodologia adotada no processo investigativo é detalhada. Posteriormente, são apresentados os resultados e a discussão referente os achados da pesquisa. Ao final, a conclusão do estudo é exposta. Por fim, as referências bibliográficas são listadas.

\section{FUNDAMENTAÇÃO TEÓRICA}

Autonomia e motivação são construtos amplamente desejáveis em todo processo de aprendizagem. O primeiro pode ser caracterizado como o controle do aprendente sobre da própria cognição, observando seus rumos e estratégias adotadas. Em relação ao segundo, esse trata de tudo aquilo torna o aluno motivado. Nesse sentido, segundo Dantas e Magno e Silva (2008, p. 150): “autonomia e motivação são uma via de mão dupla rumo ao sucesso na aprendizagem".

Há uma forte ligação entre a motivação e o desenvolvimento da autonomia estudantil. Sendo o processo de aprendizagem de línguas estrangeiras irregular e lento, torna-se necessária a existência de estímulos externos para fomentar e impulsionar o êxito, envolvendo, assim, uma importante ligação entre professor motivador e aluno autônomo. Essa ligação também pode ser estabelecida na relação aluno-aluno, por meio do conceito de autonomia distribuída proposto por Paiva (2006). Em relação a isso, ambos os discentes compartilham suas aprendizagens e estabelecem vínculos colaborativos.

Ainda, torna-se relevante abordar a distinção entre autonomia e autoinstrução, visto que o aluno autônomo não precisa excluir a presença do professor. Segundo Dantas (2008, p. 21),

\footnotetext{
a autonomia envolve o controle compartilhado entre o professor e os alunos sobre as diversas fases de aprendizagem, desde a escolha de temas e atividades até a escolha dos critérios de avaliação. Quando o professor não impõe suas escolhas, mas ouve e acolhe a dos alunos, podese dizer que padrões de controle compartilhado estão sendo implementados.
}

A visão do futuro êxito na aprendizagem compreende a preocupação de sempre atribuir o sucesso a causas internas e estáveis (USHIODA, 1996). Nesse sentido, é indispensável a presença de um professor colaborativo, visto que ele está sempre em busca de práticas facilitadoras visando o desenvolvimento da autonomia. Entre elas, é possível citar o encorajamento da reflexão sobre as formas de aprendizagem e a implementação de padrões nos quais a iniciativa parte do próprio aluno. 
Ainda em relação a isso, é importante o desenvolvimento da responsabilidade estudantil e do encorajamento na tomada de decisões, que podem corresponder tanto à própria aprendizagem quanto à forma de avaliação estabelecida em classe. Por meio da negociação, o aluno contribui com ideias e sugestões, tanto no que diz respeito à forma como será avaliado ou a respeito do conteúdo e de como irá aprendê-lo.

Estabelecer a negociação relatada no parágrafo anterior deixará o aluno mais confortável e confiante, visto que ele terá consciência de que ajudou a definir critérios em sala de aula, extinguindo o tradicional método de ensino no qual as regras são impostas sem que haja colaboração de outros agentes, a não ser o professor, que é visto como uma autoridade. Voller (1997) afirma que sem negociação, a autonomia no ensino de línguas pode se tornar um fracasso.

O processo de desenvolvimento da autonomia ganha impulso no momento em que o aluno aprende a aprender, tornando-se cada vez mais curioso e instigado a desenvolver metas envolvendo prazos e possibilidade de capacitações. Isso faz com que o estudante passe a aprender aquilo que deseja, sem mais esperar pelo momento em que o professor dará início ao estudo de determinado assunto. Nesse processo, um dos pontos relevantes refere-se ao gerenciamento da aprendizagem, que é feito pelo aprendente a partir da instauração de três níveis de controle propostos por Benson (2001), como mostra a Figura 1.

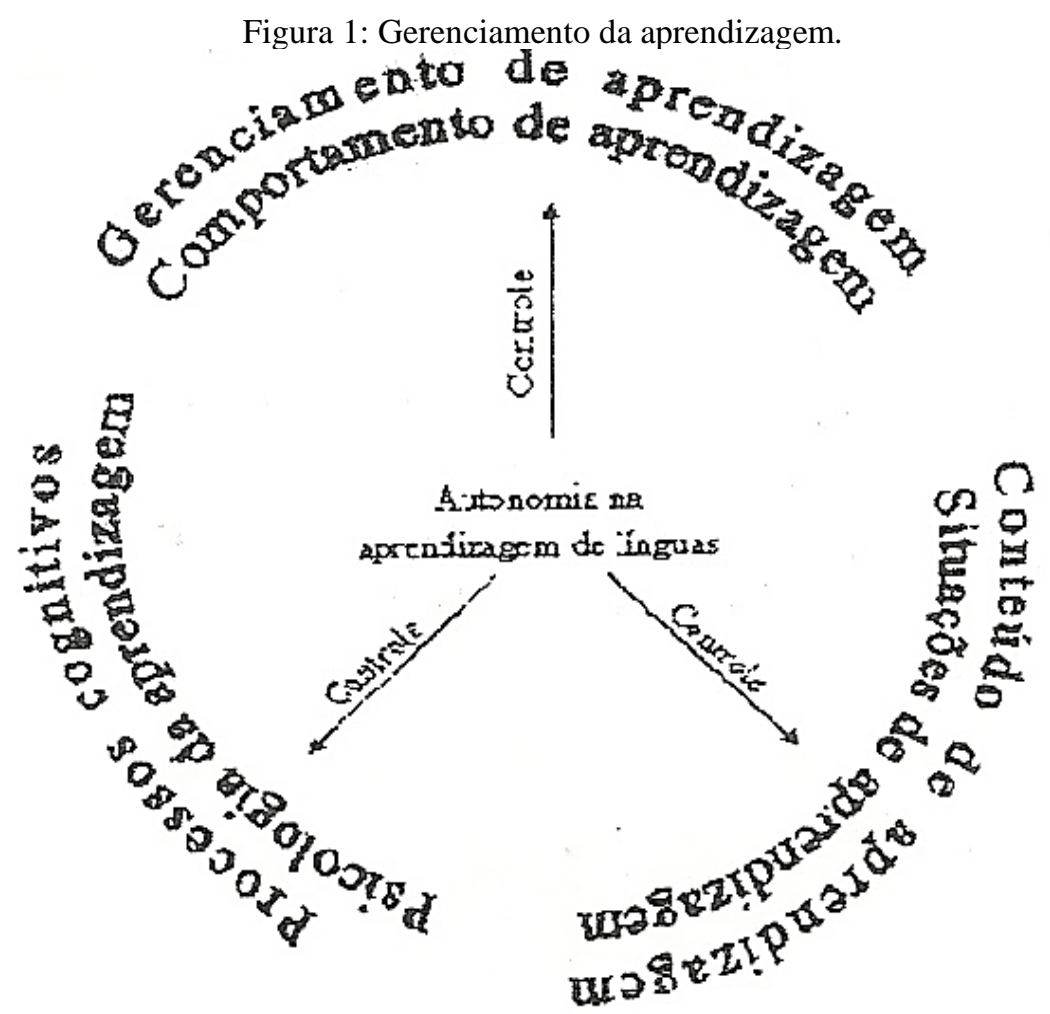

Fonte: Benson (2001, p. 50) 
No que diz respeito à Figura 1, Benson (2001) expõe que a partir do momento em que o aluno exerce controle sobre seus comportamentos e conteúdos adquiridos, bem como observa situações nas quais ele é o elemento central, pode-se dizer que esse obterá sucesso ao guiar sua aprendizagem. Em relação aos processos psicológicos envolvidos, pode-se dizer que o aprendente obterá êxito ao controlar sua aprendizagem e ao tomar conhecimento acerca dos elementos que a rodeiam.

\section{METODOLOGIA}

Visando compreender o papel da autonomia e da motivação no processo de aprendizagem de línguas, para formular esta pesquisa, os procedimentos investigativos partiram de pressupostos teóricos utilizados em sala de aula ao longo da execução da disciplina acadêmica Aprender a Aprender Língua Estrangeira.

O método pesquisa-ação foi utilizado na elaboração desta investigação na qual foi necessário acompanhar a relação estabelecida entre a professora que ministrou a disciplina mencionada no parágrafo anterior e os discentes matriculados na disciplina a fim de responder às perguntas de pesquisa.

Para este estudo, foi utilizado como objeto de análise uma turma heterogênea composta por calouros do ano de 2014 do curso de graduação em Licenciatura em Letras com habilitação em Inglês da FALEM, na UFPA, no campus Belém. A maioria desses era do sexo feminino e apresentavam situações socioeconômicas discrepantes. Em relação à faixa etária dos discentes, as idades variavam entre 17 (dezessete) e 50 (cinquenta) anos.

Na turma, 25 (vinte e cinco) alunos estavam matriculados regularmente. Dentre esses, 5 (cinco) eram iniciantes e não fluentes no idioma estrangeiro, ou seja, nunca haviam estudado inglês e possuíam pouco contato com a língua. Ademais, nenhum aluno creditou a disciplina. No entanto, dois discentes desistiram do curso no decorrer do semestre.

A docente ministrante da disciplina é professora efetiva da UFPA. Além disso, é mestre e doutora em Letras, na área de concentração em Estudos Linguísticos, e leciona no curso de Letras com habilitação em Inglês na FALEM desde 2009.

Como no turno matutino deste curso a entrada dos discentes na universidade acontece apenas na metade do ano, durante o segundo semestre de 2014, período no qual esta pesquisa foi desenvolvida, os estudantes encontravam-se no primeiro semestre da jornada acadêmica.

Com duas aulas semanais, cada uma abrangendo o período de 1h40min, nesta disciplina, não foi adotado livro didático, porém houve o estudo e a leitura de artigos científicos e capítulos de livros solicitada periodicamente pela docente. 
No final da disciplina, foi realizado um projeto intitulado Welcome To The USA, o qual foi apresentado ao público no auditório do Instituto de Letras e Comunicação (ILC), na UFPA. Seu objetivo era expor, em inglês, temas como culinária, festividade, música, cinema e esportes relacionados à cultura norte-americana.

Outro aspecto diz respeito ao ambiente onde ocorriam as aulas da disciplina: sala refrigerada, ampla e agradável, equipada com computador e projetor, os quais eram frequentemente utilizados pela professora. Ainda, havia a possibilidade de reorganização das cadeiras com a possibilidade de formação de pequenos e grandes grupos de discussão para debater o conteúdo abordado em cada aula, o que contribuiu para a maneira dinâmica como a disciplina foi ministrada.

Imergindo no meio pesquisado e adaptando-se a dois papéis: aluna e pesquisadora, ao longo de quatro meses, de setembro a dezembro, o que equivale a um semestre letivo, foram observadas as interações estabelecidas entre discentes e professora em sala de aula. As observações tiveram como foco as técnicas adotadas pela docente objetivando guiar os alunos a uma aprendizagem autônoma.

Para que o processo fosse iniciado de modo eficaz, foi necessária a introdução da noção de autonomia no léxico discente, uma vez que esse conceito implica em uma tomada de consciência do aprendente da necessidade de assumir responsabilidade por sua própria aprendizagem (BENSON, 2001), passando a se autocompreender e a entender o funcionamento de seu processo cognitivo.

\section{RESULTADOS E DISCUSSÃO}

Com a finalização da análise após o termino da disciplina, em dezembro de 2014, foi constatado que, a partir da instauração de um ambiente harmônico e propício à aprendizagem, a proposta e os objetivos expostos pela disciplina foram cumpridos de maneira bem-sucedida. Além disso, o papel desempenhado pela professora foi extremamente importante neste processo, visto que ela, por inúmeras vezes, adotou o papel de guia e facilitadora da trajetória de aprendizagem discente.

Partindo desses princípios, no decorrer da disciplina, o aluno foi motivado a tomar controle sobre seu processo de aprendizagem. Assim, o grupo de discentes foi submetido a diversos testes auto avaliativos que possuíam como objetivo a descoberta da melhor forma de aprendizagem individual, assim como da melhor maneira de estabelecer um andaime coletivo por meio da consonância cooperativa entre colegas de classe.

Com a motivação instaurada, o aluno foi instigado a aprender sozinho, já que este é o propósito da disciplina Aprender a Aprender Língua Estrangeira, implantada exatamente no primeiro semestre acadêmico, quando o aluno dá início a sua jornada acadêmica no curso de graduação.

No final do semestre, foi verificado que a disciplina fomentou maior independência entre docente e alunos. Desse modo, todos os estudantes que compareceram até a culminância da disciplina 
foram aprovados. Grande parte conquistou o conceito "excelente". Muitos ainda reportaram o desejo de continuar estudando de modo autônomo, pois, somente assim, poderiam adquirir mais fluência e proficiência no idioma-alvo.

A partir disso, observa-se que as técnicas utilizadas pela professora em sala de aula foram cruciais para a tomada de consciência do aluno e para a elevação de sua própria motivação. As técnicas mencionadas podem ser descritas como: a descoberta do estilo de aprendizagem de cada indivíduo e a adoção de estratégias de fomento às práticas autônomas.

Para isso, foram realizados testes individuais compostos por perguntas de múltipla escolha tendo como conteúdo a ser a analisado e pontuado posteriormente os temas propostos por Oxford (1990). Segundo a autora, “estratégias são ações específicas executadas pelos aprendentes para tornar o aprendizado mais rápido, mais prazeroso, mais autodirigido, mais eficaz e mais transferível para outras situações" (OXFORD, 1990, p. 8). Por isso, o modo como os aprendentes percebiam sua existência em meio ao sistema de aprendizagem foi um dos pontos mais destacados.

Outras atividades observadas foram a utilização de filmes, a produção de diários de aprendizagem e o desenvolvimento de um plano de carreira. No caso do filme, a obra analisada foi "Escritores da Liberdade", produzida por Richard LaGravenese e lançada no primeiro semestre de 2007. A produção audiovisual mencionada narra a história da relação entre professora e alunos, assim como expõe as estratégias adotadas pela docente para o desenvolvimento cognitivo dos alunos frequentadores da conflituosa e enigmática classe para a qual ministrava aulas.

No que tange aos diários, esses eram narrativas escritas individualmente em três diferentes fases do semestre: início, meio e fim. Nelas, os alunos expuseram pontos positivos e negativos a respeito das atitudes tomadas relacionadas ao rumo que a aprendizagem da língua inglesa estava tomando, relatando quais estratégias adotadas deram certo ou errado.

Os planos de carreira relataram as aspirações acadêmicas de cada estudante, colocando em prática o desenvolvimento de metas. Todas as práticas citadas foram utilizadas para avaliação. Os critérios avaliativos adotados em cada instrumento foram estabelecidos por meio da negociação com os alunos propiciada pela professora.

Os procedimentos empregados ao longo da disciplina podem ser estendidos a todo e qualquer tipo de aprendente. Desse modo, verifica-se que disparidades comuns e frequentes, como aquelas relacionadas à faixa etária, ao gênero e à situação socioeconômica, por exemplo, não se apresentam como empecilhos à aprendizagem.

Sendo assim, por intermédio da aprendizagem autônoma, em grande parte dos participantes da disciplina, padrões motivacionais foram observados em níveis elevados, o que é crucial no processo de aquisição de um idioma estrangeiro, pois a motivação é a chave para toda aprendizagem (LILE, 2002). 
Seguindo estratégias apropriadas ao estilo cognitivo particular, o indivíduo torna-se mais autônomo. Assim, "assumindo o controle pela própria aprendizagem, os aprendizes desenvolvem padrões de motivação que os levam a uma aprendizagem mais efetiva" (BENSON, 2001, p. 69).

Apesar das bem-sucedidas técnicas para tornar a disciplina Aprender a Aprender Língua Estrangeira instigante e motivadora terem sido expostas da melhor maneira possível, alguns alunos apresentaram inconformidade e indiferença para com a disciplina. Isso ocorre pois os aprendentes são diferentes, assim como são diferentes suas motivações e os usos que eles fazem ou pretendem fazer da língua. Dessa maneira, o grau de autonomia dos aprendentes também é distinto (PAIVA, 2006).

Desse modo, destaca-se o caráter psicológico do aprendente, que, estando exposto a interferências externas e a instabilidades internas, encontra-se sujeito a mudanças que podem culminar no sucesso ou fracasso da aprendizagem.

Por fim, a aprendizagem torna-se mais fácil e prazerosa quando se dá por meio de situações e elementos com os quais o aprendente esteja habituado a vivenciar, ou seja, circunstâncias em que ele se sinta confortável e que instiguem sua busca pela aprendizagem. Emoções negativas são capazes de repelir o interesse e, consequentemente, tornam o processo mais lento, desagradável e desarmônico.

\section{CONCLUSÃO}

A partir do estudo aqui exposto, conclui-se que o processo de aprendizagem autônoma pode ser realizado de inúmeras maneiras, porém, para que seja realmente eficaz, o aprendente, principal elemento e alvo deste processo, deve, primeiramente, sentir-se motivado e consciente de sua capacidade, além de compreender que suas habilidades podem e devem ser aprimoradas na medida em que as etapas evoluem.

É importante ressaltar que, geralmente, a língua inglesa é ensinada a partir da exposição do aluno a quatro habilidades, que englobam a audição (listening), a fala (speaking), a leitura (reading) e a escrita (writing). Portanto, sem a integração delas, juntamente com a autonomia e a motivação, o aprendente poderá encontrar dificuldades no decorrer de seu processo de aprendizagem. Por conseguinte, elementos como esses precisam ser gerados, desenvolvidos e mantidos nos alunos. 


\section{REFERÊNCIAS}

BENSON, P. Teaching and Researching Autonomy in Language Learning. Harlow: Pearson, 2001.

DANTAS, L. Gêneros textuais acadêmicos e ensino da língua inglesa: um caminho para a motivação e a autonomia. 2008. 174 f. Dissertação (Mestrado em Estudos Linguísticos) Universidade Federal do Pará, 2008.

DANTAS, L.; MAGNO E SILVA, W. Motivação e autonomia para a formação de um novo aprendente e de um novo professor. In: ASSIS, R. (Org.). Estudo da língua portuguesa e de todas as línguas que fazem a nossa. Belém: Editora Unama, p. 139-151, 2008.

DICKINSON, L. Learner autonomy: what, why and how? In: Leffa, V. Autonomy in Language Learning. Porto Alegre: Editora da Universidade, p. 2-12, 1994.

LILE, W. Motivation in the ESL Classroom. The Internet TESL Journal, v. 11, n. 1, 2002.

OXFORD, R. Language Learning Strategies: What every teacher should know. Boston: Heinle \& Heinle, 1990.

PAIVA, V. Autonomia e complexidade. Linguagem \& Ensino, Pelotas, v. 9, n. 1, p. 77-127, 2006.

USHIODA, E. Learner autonomy: the role of motivation. Dublin: Authentik, 1996.

VOLLER, P. Does the teacher have a role in autonomous language learning? In: BENSON, P.; VOLLER, P. (Ed.) Autonomy \& Independence in Language Learning. London: Longman, p. 98113, 1997. 